\title{
Amazônia, fronteiras econômicas e a sustentabilidade do licenciamento ambiental em grandes projetos
}

\author{
Amazon, economic frontiers and the sustainability of the environmental licensing \\ process in large projects
}

\author{
Francisco del Moral Hernandez ${ }^{1}$
}

Artigo recebido para publicação em jun./2015 e aceito para publicação em jun./2015

\section{RESUMO}

O artigo discute alguns dos recentes projetos hidrelétricos e da indústria da mineração, propostos e em andamento na Amazônia brasileira, apresentando aspectos problemáticos referentes aos processos de licenciamento ambiental e inadequações conceituais que comprometem a caracterização da conversão hidrelétrica como ação técnica sustentável. O artigo se ampara na análise de planos governamentais de expansão da oferta de eletricidade no sentido de produzir uma reflexão sobre o direcionamento interno da energia gerada e sua repartição por setores industriais. Também traz os números da expansão mineral em extração bruta e a decorrente exportação de energia incorporada nos produtos comercializados, com o intuito de caracterizar os direcionamentos dos benefícios econômicos e os custos ambientais que permanecem nos locais de origem. Por meio da seleção e análise de alguns casos reais em processo de licenciamento, foram identificados alguns problemas graves que não foram tratados seja no âmbito dos estudos ambientais necessários para o licenciamento, seja no processo político de tomada de decisão. A superposição ou proximidade entre áreas de proteção e as áreas afetadas pelos empreendimentos e efeitos cumulativos de impactos ambientais, como o desmatamento e seccionamento múltiplo de trechos de um mesmo rio também se evidenciam como temas importantes a serem debatidos e aprofundados no que venha a se chamar de sustentabilidade de projetos.

Palavras-chave: Licenciamento Ambiental, Impactos Ambientais, projetos de infraestrutura, sustentabilidade de grandes projetos, Amazônia.

\begin{abstract}
The article discusses some of the recent hydroelectric projects and mining industry forecasting in, proposed and in progress in the Brazilian Amazon and presents problems regarding environmental licensing processes and conceptual inadequacies that compromise the characterization of hydroelectric conversion as sustainable technical activity. The article also supports the analysis of governmental plans of expanding the supply of electricity in order to produce an overview about the internal distribution of the energy generated and how it is shared among industrial sectors. It also brings expressive numbers of mineral extraction expansion and the resulting embodied energy export in mineral commodities, in order to characterize the directions of economic benefits and the
\end{abstract}

$1 \quad$ Doutor em Ciências da Energia pela Universidade de São Paulo. Mestre em Energia pela USP. Tem especialização em Planejamento Energético (UNICAMP), formou-se Engenheiro Eletricista também pela UNICAMP. Docente na Faculdade de Tecnologia de Jundiaí (FATEC Jundiaí, Centro Estadual de Educação Tecnológica Paula Souza) no curso de Gestão Ambiental e no curso de Engenharia Ambiental da Universidade Estadual Júlio de Mesquita Filho (UNESP), Campus de Sorocaba. Desenvolve estudos e pesquisas na área de energia sociedade e ambiente nos últimos treze anos, especialmente acompanhando processos de licenciamento ambiental, análises de estudos de impacto ambiental e tomada de decisão. E-mail. prof.francisco@fatecjd.edu.br e prof.francisco@fatec.sp.gov.br. 
Revista Tecnologia e Sociedade, Curitiba, v. 11, n. 22, 2015

Edição Especial XII Encontro Nacional de Engenharia e Desenvolvimento Social

ISSN (versão online): 1984-3526

ISSN (versão impressa): 1809-0044

environmental costs that remain in those places of origin. Through the selection of some real cases in the licensing process, serious problems were identified since those have not been properly examined either under the environmental studies required for the licensing, or in the political decision-making process. The superposition or proximity between protected areas and areas affected by projects and cumulative effects, such as deforestation and sectioning of multiple paths from a same river also raised as important issues to be more deeply debated in the so called sustainable projects.

Key Words: Environmental licensing, environmental impacts, infrastructure projects, sustainability of projects, Amazon.

\section{INTRODUÇÃO}

O arcabouço teórico deste artigo se ampara na coleta e discussão de alguns discursos predominantes que vão de encontro à legitimação política de grandes obras na área de mineração e produção de eletricidade e que são propostos em áreas ambientalmente sensíveis, unidades de conservação e terras indígenas homologadas e áreas de atividades econômicas e sociais de populações tradicionais. Procura-se no desenvolvimento do artigo levantar alguns pressupostos de análise e identificar problemas centrais nos processos de licenciamento ambiental, colocando-os lado a lado, em análise, com o discurso da sustentabilidade em alguns de seus aspectos. Os pressupostos de análise se constituem em leis elementares da conservação de energia e cálculos de eficiência globais e que são confrontados com situações reais propostas em empreendimentos hidrelétricos e em planos de expansão na extração mineral e de produção de setores com alto consumo de eletricidade.

Os procedimentos de licenciamento ambiental de grandes obras tem mostrado, no período mais recente, que há um predomínio de discussões isoladas, projeto a projeto e questões mais amplas ligadas à sustentabilidade de áreas protegidas. A própria sustentabilidade dos modos de vida tradicionais e dos ecossistemas ao longo dos rios que vão sendo sucessivamente seccionados vai sendo posta à prova.

Esta análise de planos governamentais, que envolvem tendências de expansão produtiva e lacunas dos problemas no licenciamento ambiental de casos selecionados, e finalmente uma discussão técnica sobre a vida útil de hidrelétricas, fundamentam as considerações finais do artigo sobre a sustentabilidade do próprio licenciamento ambiental tal como se constitui hoje. 


\section{HIDRELÉTRICAS, PRESSUPOSTOS DE ANÁLISE E OS MITOS ASSOCIADOS DA CONVERSÃO EFICIENTE E POUCO DEGRADANTE DO AMBIENTE.}

A formulação do problema da utilização de vários recursos naturais como rios, suas águas, as terras ribeirinhas, matéria e energia não foge ao esquema básico da mera ampliação da capacidade instalada do presente projetada para o futuro. Não é de maneira fortuita que predomina o discurso do crescimento, do desenvolvimento (seja na chamada crise ou na euforia do pós-crise). Há alguns indicadores que são muito utilizados e, um deles, o crescimento do Produto Interno Bruto (PIB) ou a taxa de crescimento do PIB, parece estabelecer-se como critério do qual não se escapa e baliza o discurso do planejamento, muito embora o ambiente do planejamento seja bastante hermético e, do ponto de vista da discussão pública, quase inacessível.

Em resumo, se vislumbra para o futuro a situação presente ampliada: o aumento da oferta de energia amparado no discurso da expansão, ampliação das solicitações de atividade de mineração em unidades de conservação, adensamento de estradas em áreas protegidas, leilão de petróleo não convencional próximo a áreas ambientalmente sensíveis, superposição de reservatórios de hidrelétricas com unidades de conservação (ilegalidades resolvidas administrativamente, por exemplo, com alterações na lei, através de decretos).

O planejamento e construção de barragens hidrelétricas na região amazônica deixaram de ser apenas uma questão nacional relacionada com o tema de segurança energética nacional e vem se conformando como desafios regionais no âmbito da diplomacia, da política e dos interesses econômicos transfronteiriços. O volume de recursos associados à construção destas grandes obras, a presença das grandes empreiteiras da área da construção civil, a comercialização dos equipamentos necessários (como turbinas, geradores, transformadores), os consórcios associados às longas redes de transmissão de energia, as fontes de financiamento, a composição acionária dos consórcios construtores, geradores e transmissores de energia mostram uma ramificação de interesses econômicos de conexões internacionais. Em momento em que a situação econômica mundial enseja ampliação de negócios e contratos, vários deles são assinados para empreendimentos de infraestrutura exploratória mineral e energética na porção norte do país. 
Revista Tecnologia e Sociedade, Curitiba, v. 11, n. 22, 2015

Edição Especial XII Encontro Nacional de Engenharia e Desenvolvimento Social

ISSN (versão online): 1984-3526

ISSN (versão impressa): 1809-0044

A argumentação que ampara o discurso legitimador do processo expansivo de oferta de energia e exploração mineral siderúrgica passa por conceitos como soberania nacional, segurança energética e pela inserção do Brasil como protagonista econômico no cenário latino americano. Estes argumentos presentes em planos governamentais e na justificativa das grandes obras constrangem a discussão ambiental associada à produção de energia.

Os empreendimentos de infraestrutura energética, por serem intensivos na utilização dos recursos naturais, deixam consequências e registros volumosos dos passivos sociais e ambientais evidenciados na historiografia, na ecologia e na sociologia relacionadas à energia (SEVA Fo, 1988, 2004, 2005a\&b, 2007, 2008, 2010; SANTOS \& ANDRADE, 1988; FEARNSIDE, 2014; MAGALHÃES, 1990, 2007; $M A B, 2009)$. As novidades contemporâneas no processo de legitimação de grandes obras aparecem na ênfase da ideia de matriz energética limpa, baseada na hidreletricidade e na presença de imensos recursos naturais, tidos como vantagens econômicas comparativas, a exemplo do minério de ferro, bauxita, níquel, cobre manganês, estanho, ouro, reservas que se estabelecem superpostas ou próximas a áreas protegidas, ou a terras indígenas ou relativamente próximas a empreendimentos hidrelétricos em operação, propostos ou em construção. O caso recente do empreendimento de mineração Belo Sun, proposto na área diretamente afetada pela hidrelétrica de Belo Monte na Volta Grande do Xingu, PA (ver Figura 1), é elucidativo de como os processos de licenciamento ambiental vão se sucedendo com o tempo. Aninhados no processo multiplicativo de licenciamentos ambientais, falham na caracterização das áreas diretamente afetadas também de maneira sucessiva quando seguidos empreendimentos são propostos e não foram tratados por seus aspectos cumulativos em termos de avaliação de impacto ambiental tal como preconizado pelas boas praticas de avaliação prévia (SANCHEZ, 1991; WATHERN, 1988; WCD, 2000; EC, 1999; LARRY et al, 2010; EPA, 1999; McCOLD et al, 1996).

As duas terras indígenas localizadas ao longo da Volta Grande do Xingu, bem como longos trechos de terras ribeirinhas, não foram consideradas como diretamente afetadas no licenciamento ambiental da usina hidrelétrica de Belo Monte (Rio Xingu, PA), o que se notabilizou como desfiguração do processo de licenciamento da referida hidrelétrica (MAGALHÃES \& HERNANDEZ, 2011). 


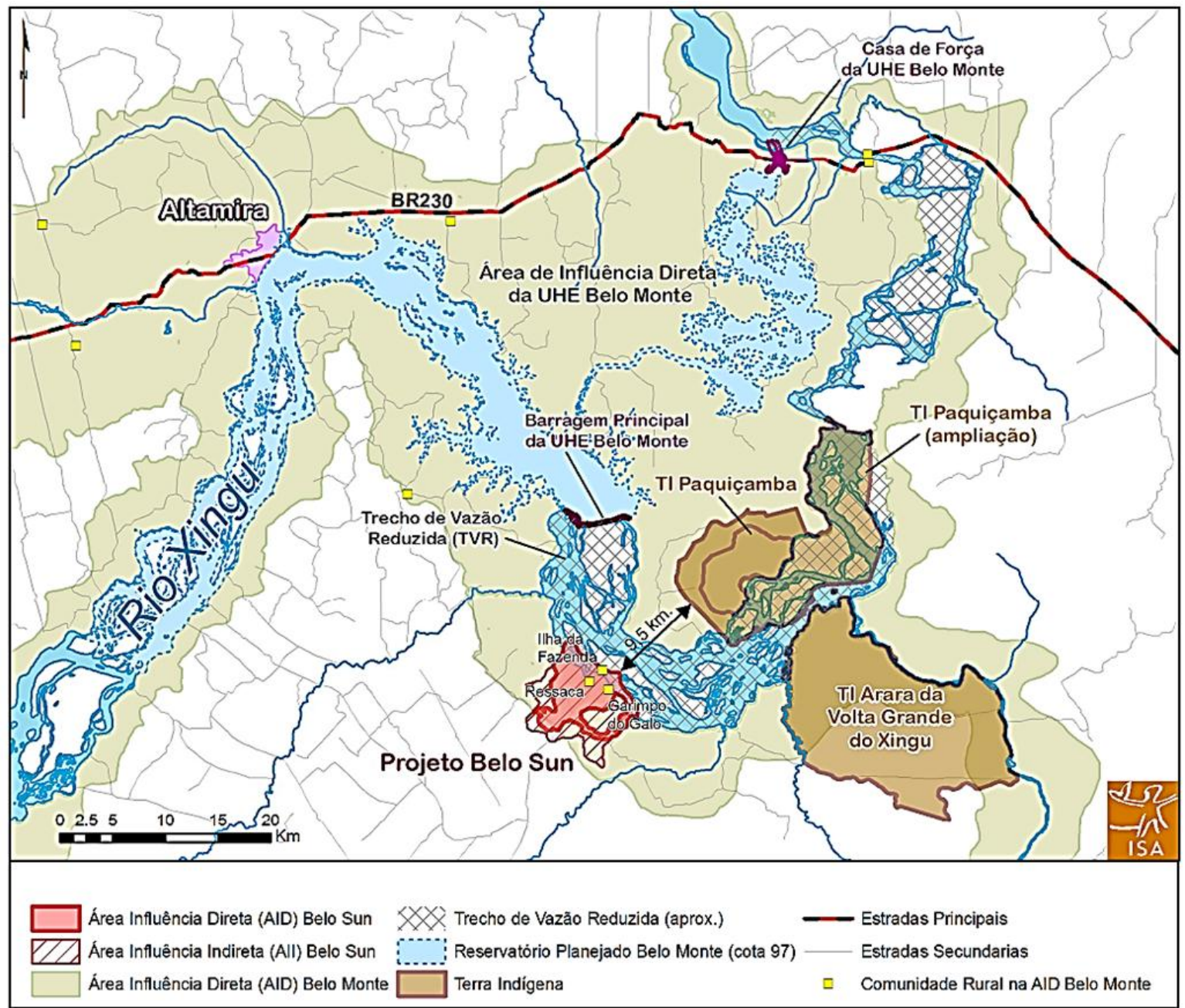

Figura 1. Representação da Área de Influência Direta e Indireta do meio físico do Projeto Volta Grande da Belo Sun (em vermelho), em perspectiva com a Área Diretamente Afetada (ADA) da UHE Belo Monte - que inclui o Trecho de Vazão Reduzida, o Reservatório do Canal e o Reservatório do Xingu -, e com a AID física e biótica da Usina (em marrom claro). Em destaque, a Terra Indígena Paquiçamba, após ampliação realizada pela FUNAI em outubro de 2012. Fonte: ISA (2013).

As usinas hidrelétricas (UHEs) têm amarras naturais ligadas ao meio biofísico: as UHEs precisariam avisar os rios sobre suas expectativas e como eles deveriam se comportar para obter a potência máxima instalada, fator normalmente utilizado quando da divulgação de novos projetos propostos. No entanto, há perdas em cada conversão: a conversão da energia potencial gravitacional presente em uma massa de água acumulada, submetida a certo desnível, se transforma em energia cinética pelo seu escoamento pelos dutos forçados, ganha energia cinética que se converte em energia de rotação transmitida ao eixo das turbinas. No estágio final, as turbinas acopladas aos geradores convertem essa energia de rotação em energia elétrica pelo deslocamento relativo de campos eletromagnéticos girantes e fixos. Cada estágio têm eficiências altas se individualmente analisadas. Porém em cada transformação há perdas que se acumulam conforme os equipamentos vão sendo 
acoplados. Como valores típicos, espera-se que uma turbina tenha eficiência de cerca de $90 \%$ (figura 2a), assim como o gerador. Acoplados, gerador e turbina, tal como indica a figura $2 \mathrm{~b}$, a eficiência de conjunto será obtida pelo produto das eficiências parciais: um valor típico em torno de $81 \%$, que já exibe números menores se comparados à eficiência dos estágios intermediários tomados isoladamente.

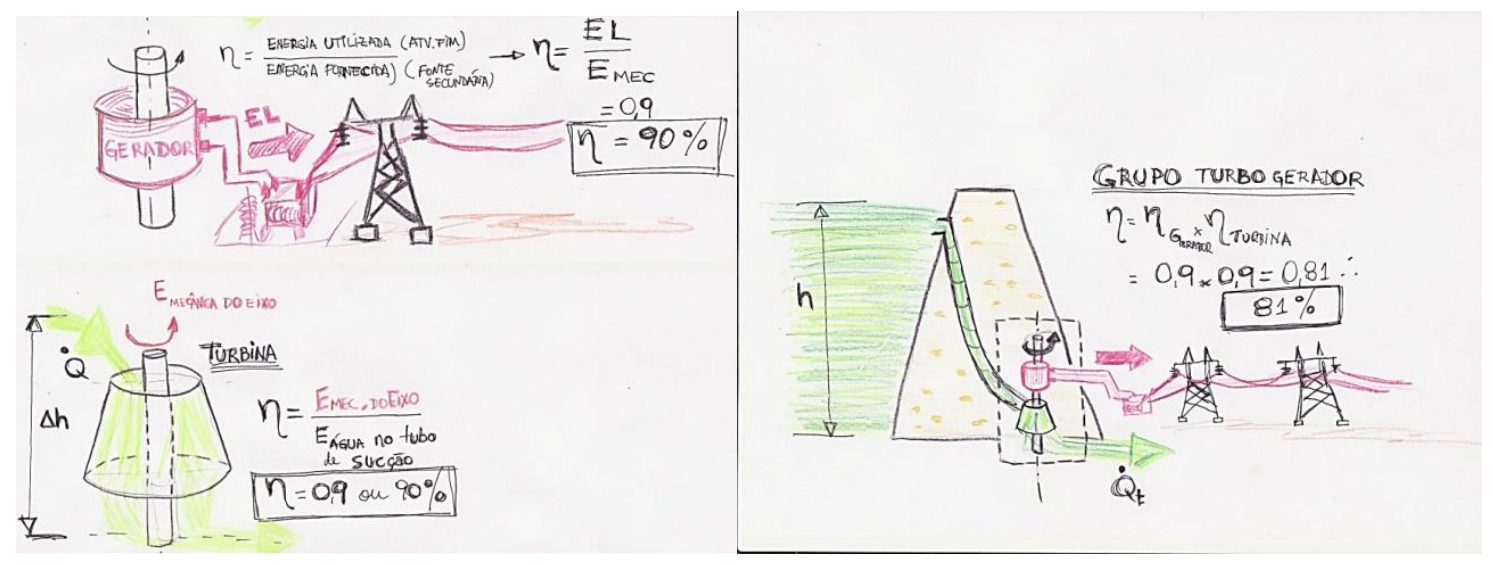

Figura 2. (a) Valores típicos de eficiências parciais de turbina e gerador na conversão hidrelétrica. (b) Eficiência de acoplamento turbina e gerado: valores típicos.

Se estivermos interessados no balanço energético global da usina, entendendo a energia total contida em uma massa de água constrangida em seu movimento por um represamento, e confrontar esse balanço energético com o esforço tecnológico e o conjunto de consequências ambientais e sociais deste represamento, poderíamos aproximar a discussão de sustentabilidade ambiental com a obtenção de certa eficiência de conversão. A figura 3 ilustra essa aproximação. Na figura vê-se um diagrama esquemático em que um grande volume de água é represado, sendo parte escoado pela rota das turbinas e parte direcionado aos vertedouros, rota na qual não se aproveita a conversão mecânicoelétrica de energia. Alguns poderiam dizer que é água saindo pelo "ladrão", outros poderiam dizer que é água mantendo a operação segura do reservatório, outros poderiam dizer que se trata de um "rio", mas administrado em suas vazões.

O fato é que a dinâmica do rio e os usos dá agua e das beiras de rios foram alterados por um barramento. Se imaginarmos arbitrariamente que a vazão permitida rio abaixo se divide em duas metades (50\% na rota das turbinas e $50 \%$ pelo vertedouro) o balanço energético total do arranjo técnico já deve cair pela metade dos $81 \%$ anteriormente mencionados. Ou seja, a eficiência global cairia a aproximadamente $40 \%$. Este valor é o que deve confrontar aspectos relacionados à 
consequência ambiental do represamento e o dado real de conversão entre as modalidades de energia em uma hidrelétrica, se estivermos interessados em falar em sustentabilidade de uma grande obra dessa natureza. Leis elementares da conservação da energia são as que devem ser utilizadas na discussão ambiental.

Note-se que não estamos englobando aqui outro fluxo que é a quantidade de água encaminhada pela rota evaporativa do reservatório, algo absolutamente importante nos casos de reservatórios para regularização em usinas hidrelétricas. Exemplos marcantes são as usinas no rio São Francisco como Sobradinho, BA (o caso mais expressivo, com $4.214 \mathrm{~km}^{2}$ de área, $130 \mathrm{~m}^{3} / \mathrm{s}$ de vazão evaporativa, o que representa cerca de 7\% da vazão do rio à jusante do reservatório), Três Marias (MG) e Itaparica na divisa da Bahia com Pernambuco (PEREIRA, 2004; RIBEIRO et al, 2007; PEREIRA et al, 2009; ONS, 2004).

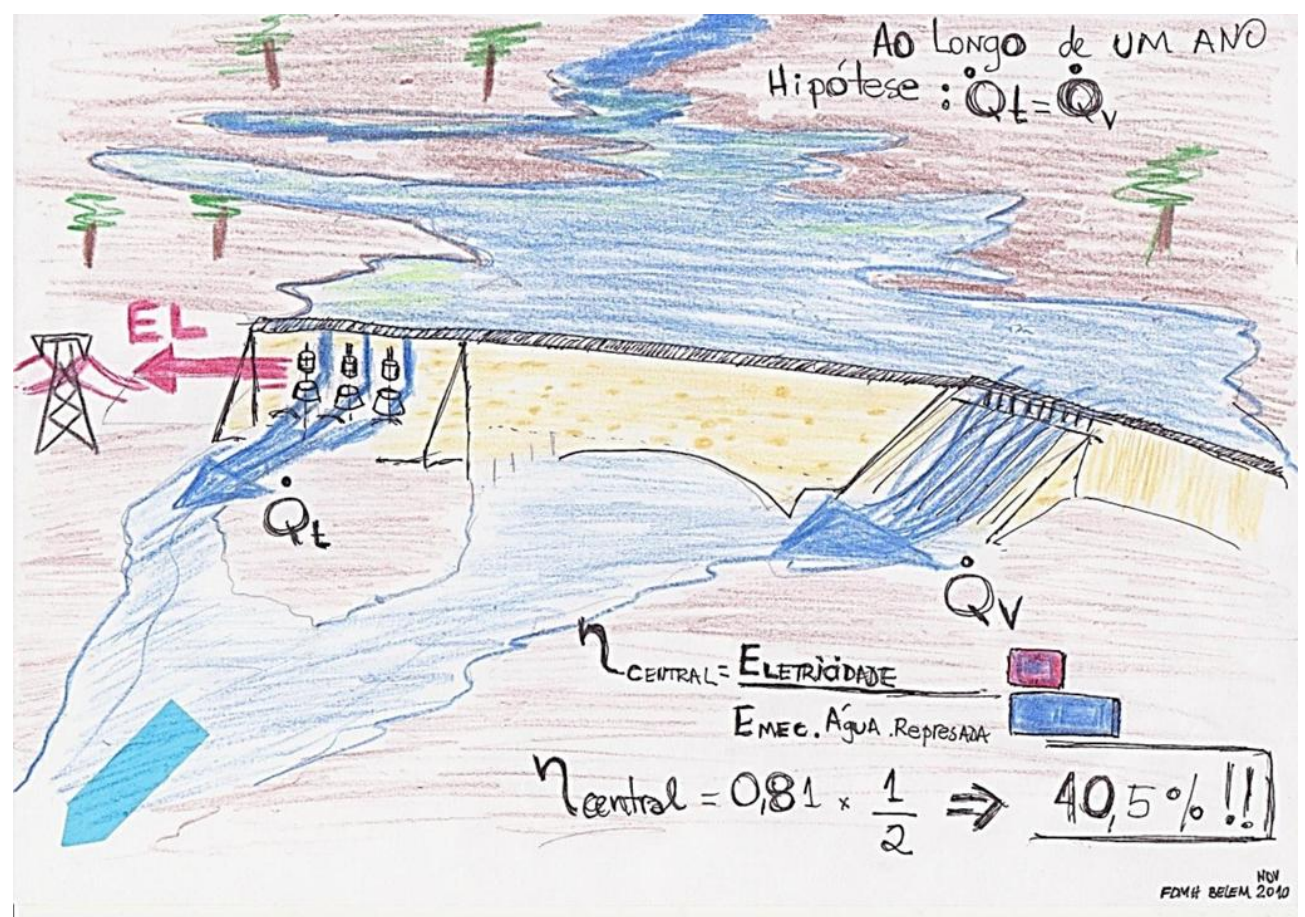

Figura 3. Eficiência global de uma turbina hidrelétrica com reservatório de acumulação e repartição de vazão entre a rota das turbinas $(Q t)$ e a rota dos vertedouros $(Q v)$. Neste exemplo considerou-se arbitrariamente uma condição de operação em que $Q t=Q v$.

\section{O DIRECIONAMENTO INTERNO DA ENERGIA GERADA E REPARTIÇÃO POR SETORES}


É comum ler, em cada um dos relatórios e estudos de impacto ambiental de projetos hidrelétricos de grande porte, que haverá benefícios regionais no atendimento da energia elétrica gerada. Devemos, no entanto, levar em conta que uma vez que uma usina é construída e acoplada ao sistema elétrico interligado nacional (SIM) a energia não tem um destino definido (ver Figura 4, que exibe as conexões existentes no sistema elétrico nacional). $\mathrm{Na}$ verdade a energia elétrica gerada será direcionada para os centros de carga onde houver demanda instantânea por essa energia. Nosso país se caracteriza por atender a uma concentrada demanda dos setores eletrointensivos (que consomem intensivamente energia elétrica como insumo). Já a demanda residencial (principalmente pela dificuldade de se aferir um ritmo de crescimento da oferta, muito dependente do gasto familiar e suas variações) vem sofrendo um processo de exclusão social relativo, no acesso à energia elétrica, sobretudo no valor das tarifas, uma vez que sabe-se que as tarifas brasileiras de energia elétrica para consumidores de pequeno/médio porte estão entre as maiores do mundo (FIRJAN, 2011). 


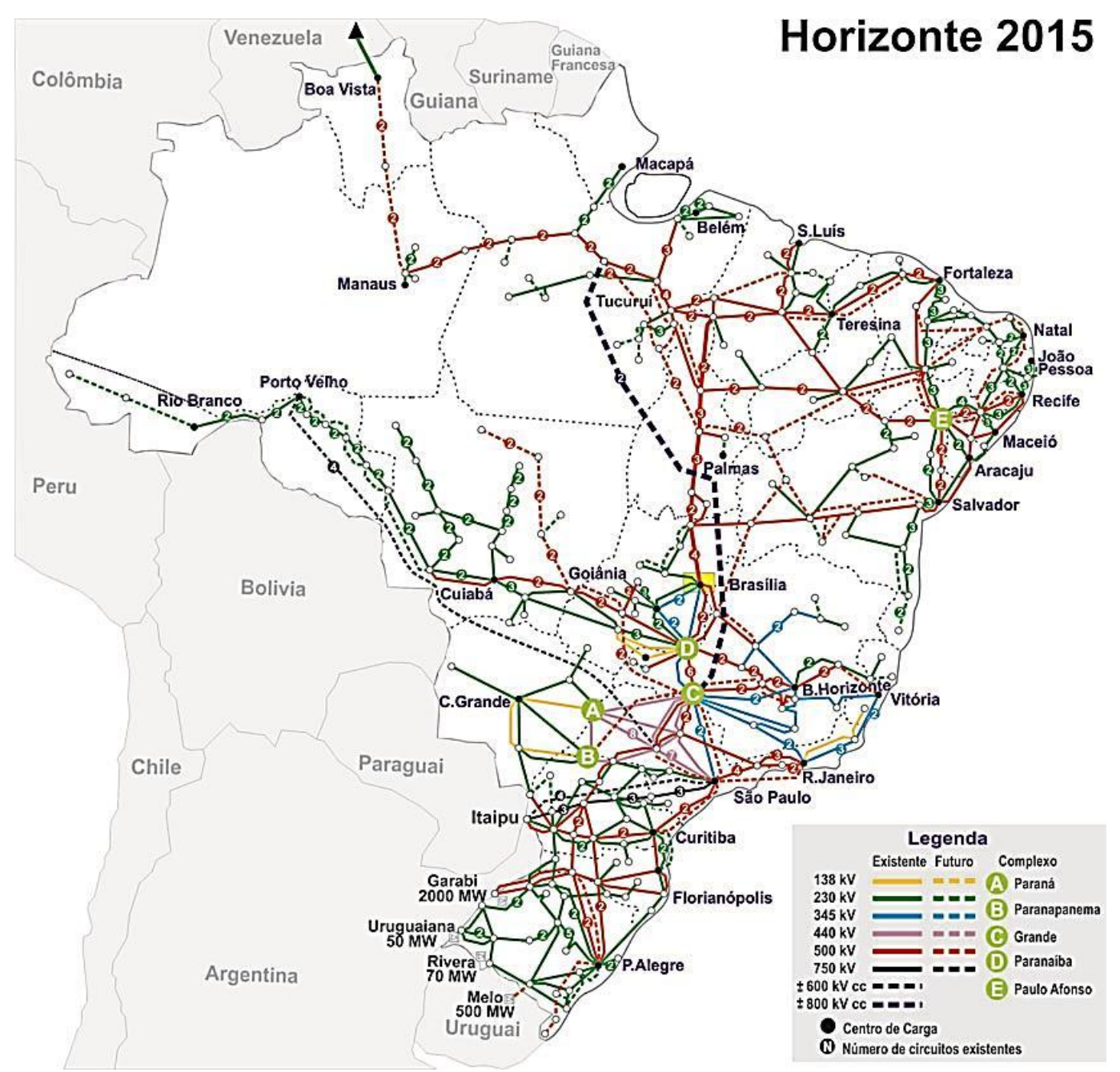

Figura 4. Sistema elétrico Nacional. Traçados existentes e projetados e classes de tensão.

Fonte: ONS, Operador Nacional do Sistema Elétrico. Mapas do SIN. ${ }^{2}$

As longas linhas de transmissão (linhões) já consolidadas (e outras projetadas) para o segundo ciclo de grandes hidrelétricas na região (Santo Antônio e Jirau, Belo Monte e Complexo Teles Pires e Tapajós) precisam percorrer mais de 3 mil quilômetros de extensão em alta voltagem para atingir os núcleos dos grandes centros consumidores. Esta energia se encontra à disposição de plantas industriais eletrointensivas (que consomem grandes quantidades de energia elétrica por tonelada produzida, fator também conhecido como intensidade energética), onde quer que elas estejam e comparativamente a preços mais baratos, o que estimula estes setores a aumentar sua capacidade instalada, uma vez que o insumo eletricidade se torna mais convidativo em preço e oferta abundante, através de subvenções tarifárias que se renovam a cada ciclo de avaliação de contratos de grandes blocos de energia comercializada.

\footnotetext{
${ }^{2}$ Disponível em: http://www.ons.org.br/conheca sistema/mapas sin.aspx
} 
Revista Tecnologia e Sociedade, Curitiba, v. 11, n. 22, 2015

Edição Especial XII Encontro Nacional de Engenharia e Desenvolvimento Social

ISSN (versão online): 1984-3526

ISSN (versão impressa): 1809-0044

Os números das projeções de aumento da capacidade instalada destes setores são expressivos e evidenciados pelos dados da Tabela I. Estes mostram as expectativas de consumo anual de eletricidade por segmento da indústria e taxas de crescimento da produção física, que estão identificadas também quanto à sua relação com a atividade exportadora na Figura 5.

\begin{tabular}{|c|c|c|c|c|}
\hline Segmento & 2012 & 2017 & 2022 & $\begin{array}{c}2012- \\
2022 \\
\text { (\% ao ano) }\end{array}$ \\
\hline Alumínio & 21.707 & 22.446 & 23.006 & 0,6 \\
\hline Alumina & 3.225 & 3.791 & 4.256 & 2,8 \\
\hline Bauxita & 499 & 567 & 628 & 2,3 \\
\hline Siderurgia(aço bruto) & 20.453 & 24.291 & 29.586 & 3,8 \\
\hline Pelotização & 2.886 & 3.618 & 3.969 & 3,2 \\
\hline Ferroligas & 9.675 & 13.057 & 14.514 & 4,1 \\
\hline Cobre & 455 & 680 & 732 & 4,9 \\
\hline Soda-Cloro (soda) & 4.307 & 4.747 & 4.939 & 1,4 \\
\hline Petroquímica (eteno) & 6.144 & 6.645 & 9.181 & 4,1 \\
\hline Celulose & 14.538 & 20.951 & 26.536 & 6,2 \\
\hline Pasta Mecânica & 1.095 & 1.075 & 1.058 & $-0,3$ \\
\hline Papel & 8.370 & 10.248 & 12.661 & 4,2 \\
\hline Cimento & 7.057 & 8.954 & 11.525 & 5,0 \\
\hline Total & 100.412 & 121.070 & 142.590 & 3,6 \\
\hline
\end{tabular}

Tabela I - Grandes consumidores industriais: consumo anual de eletricidade GW.h.

Fonte: EPE (Empresa de Pesquisa Energética), 2012. 




Figura 5. Taxa expectativa de crescimento da capacidade instalada de alguns setores industriais selecionados. Fonte: Fonte: EPE (Empresa de Pesquisa Energética). 2013.

A Tabela II mostra a produção física destes segmentos e a expectativa de aumento da produção no período 2012 - 2022. Estes números expressivos são os que dão baliza aos planos de expansão da oferta de eletricidade e ampliam a geografia política e econômica no território dos planos, expandindo a chamada fronteira hidrelétrica da Amazônia. O que deve ser notado é que esta expansão de fronteira hidrelétrica se conecta com rotas de exportação de produtos e energia neles incorporada. O cenário verificado é que a região amazônica se transforma de maneira acelerada em província mineral, hidrelétrica e bastante internacionalizada. Esta região abriga simultaneamente áreas possíveis de ampliação da oferta de hidreletricidade face ao potencial hidráulico de suas bacias, mas trata-se de áreas que por sensibilidade ambiental restringem, em tese, o aproveitamento integral deste potencial (TABELA V). Do ponto de vista da discussão sobre a qualidade dos processos de licenciamento ambiental contemporâneos este é centro da controvérsia. 
Revista Tecnologia e Sociedade, Curitiba, v. 11, n. 22, 2015

Edição Especial XII Encontro Nacional de Engenharia e Desenvolvimento Social

ISSN (versão online): 1984-3526

ISSN (versão impressa): 1809-0044

\begin{tabular}{lccc}
\hline Segmento & $\mathbf{2 0 1 3}$ & $\mathbf{2 0 1 8}$ & $\mathbf{2 0 2 3}$ \\
Alumínio & 1.415 & 1.467 & 1.467 \\
Alumina & 11.334 & 14.297 & 16.530 \\
Bauxita & 42.680 & 47.425 & 50.724 \\
Siderurgia (aço bruto) & 35.472 & 46.070 & 46.650 \\
Pelotização & 59.232 & 81.072 & 95.472 \\
Ferroligas & 901 & 1.443 & 1.623 \\
Cobre & 340 & 459 & 548 \\
Soda-Cloro (soda) & 1.436 & 1.501 & 1.780 \\
Petroquímica (eteno) & 3.653 & 3.653 & 3.653 \\
Celulose & 14.017 & 19.681 & 23.063 \\
Pasta Mecânica & 439 & 460 & 468 \\
Papel & 10.565 & 13.488 & 17.359 \\
Cimento & 71.161 & 90.297 & 113.882 \\
\hline $\begin{array}{l}\text { Tabela II - Grandes consumidores industriais de energia elétrica: produção física } \\
\text { Fonte: EPE (Empresa de Pesquisa Energética). } 2013 .\end{array}$ & \\
\hline
\end{tabular}

Em termos de orientação de política industrial e de planejamento da oferta e atendimento de demanda o que chama a atenção é que o uso final a ser feito da energia não tem sido objeto de debate aberto no Brasil. Por um lado, os índices de consumo específico de energia por tonelada produzida tornam clara a caracterização dos setores que consomem muita energia (o que abriria espaço para a salutar discussão de aumento da eficiência nos processos). Por outro lado, há indicadores que mostram outras ineficiências de ordem social: a fundição de alumínio para exportação é um dos casos mais extremos e de destaque, fornecendo apenas 2,7 empregos por GWh de eletricidade consumida (BERMANN, 2002).

\section{OS GRANDES NÚMEROS DA EXPANSÃO MINERAL EM EXTRAÇÃO BRUTA E EXPORTAÇÃO DE ENERGIA INCORPORADA}

Sempre há necessidade de diferenciar o porte das atividades de extração mineral. Atividades em menor escala e até mesmo subterrâneas que, embora tenham efeitos negativos, podem ter melhor manejo em termos de agressão 
Revista Tecnologia e Sociedade, Curitiba, v. 11, n. 22, 2015

Edição Especial XII Encontro Nacional de Engenharia e Desenvolvimento Social

ISSN (versão online): 1984-3526

ISSN (versão impressa): 1809-0044

ambiental e degradação de áreas, situação completamente distinta da mega mineração a céu aberto como a que ocorre, por exemplo, na província mineral em Carajás (PA). As jazidas com a maior concentração de minerais, e mais acessíveis, já estão em exploração há muitos anos e vão se se esgotando. Buscam-se depósitos de menor qualidade e, por conseguinte, é necessário remover maiores volumes de rochas, para obter uma mesma quantidade de minério. Esta opção técnica é possível e viável economicamente porque a demanda internacional e os preços globais são muito altos, muito embora haja flutuações que façam o preço do minério cair. A flutuação negativa de preço é absorvida face ao grande volume de reservas desta imensa jazida. A mega mineração é uma atividade econômica globalizada, internacionalizada. Particularmente no comércio Brasil-China ocorre outro fenômeno, mais vinculado à geopolítica e à segurança energética mineral: a grande rota dos navios graneleiros abastecem pátios no território do parceiro comercial do oriente, mesmo a preços internacionais baixos, minério de ferro que alimentará a produção siderúrgica do aço naquele pais e não no pais de origem, onde se extrai o minério bruto.

Quando se pensa, de maneira combinada, na quantidade de energia elétrica incorporada nesses produtos primários, pode-se entender o ciclo, digamos, de exportação de energia, uma vez que se trata de insumo básico que deixa de ser consumida no país destino. Bermann (2012) expõe essa problemática associando-a a opções de politica industrial, fazendo a conexão do prejuízo ambiental associado à produção de energia elétrica (por fonte hidrelétrica, com seus custos ambientais e sociais altíssimos) para dar suporte a essa "transposição" sofisticada de fatores de produção.

Vejamos os números exibidos como resultado de suas pesquisas: a produção de minério de ferro, que em 2008 foi de 319 Mt (milhões de toneladas), crescerá para $585 \mathrm{Mt}$ em 2015, para $795 \mathrm{Mt}$ em 2022, até chegar a escala impressionante de 1.098 Mt em 2030 (cf. Plano Nacional de Mineração 2030). Já a produção de aço, que foi de $33.716 \mathrm{mt}$ (mil toneladas) em 2008, aumentará sua produção para 52.550 mt em 2014 e atingirá $72.312 \mathrm{mt}$ em 2019. A expansão da produção de ferro-ligas também é expressiva, de $984 \mathrm{mt}$ em 2008 para $1.490 \mathrm{mt}$ em 2014 e $1.870 \mathrm{mt}$ em 2019. O Plano Decenal de Energia para o horizonte até 2020 (PDE 2020) trazia a previsão mais recente de $2.060 \mathrm{mt}$ para aquele ano limite. A produção de alumínio 
Revista Tecnologia e Sociedade, Curitiba, v. 11, n. 22, 2015

Edição Especial XII Encontro Nacional de Engenharia e Desenvolvimento Social

ISSN (versão online): 1984-3526

ISSN (versão impressa): 1809-0044

primário, que foi de $1.661 \mathrm{mt}$ em 2008, teria aumento para $2.070 \mathrm{mt}$ em 2019. O PDE 2020 (elaborado em 2011), mostra a previsão de $2.537 \mathrm{mt}$ em 2020. Os dados estão sintetizados nas tabelas III e IV.

\begin{tabular}{lcccc}
\hline Produtos & Produção & Produção & Exportação & Exportação \\
& $\mathbf{2 0 0 0}$ & $\mathbf{2 0 0 8}$ & $\mathbf{2 0 0 0}$ & $\mathbf{2 0 0 8}$ \\
Minério de ferro & 212.576 & 319.000 & 116.630 & 232.000 \\
Alumínio & 1.277 & 1.661 & 760 & 748 \\
Siderurgia(aço bruto) & 27.865 & 33.716 & 49.617 & 9.290 \\
Ferroligas & 903 & 984 & 534 & 358 \\
Celulose & 7.463 & 12.697 & 3.155 & 6.892 \\
Papel & 7.200 & 9.410 & 1.332 & 1.757 \\
\hline
\end{tabular}

Tabela III - evolução da produção e exportação de produtos primários no Brasil 2000-2008 (mil toneladas). Fonte: BERMANN, 2012.

\begin{tabular}{lcc}
\hline Produtos & Produção & Exportação \\
& & \\
Minério de ferro & $8.870,0$ & $7.140,0$ \\
Alumínio & $25.247,2$ & $11.369,6$ \\
Siderurgia (aço bruto) & $18.543,8$ & $5.109,5$ \\
Ferroligas & $7.143,8$ & $2.599,1$ \\
Celulose & $11.300,3$ & $6.133,9$ \\
Papel & $6.587,0$ & 9.410 \\
Total & $77.692,1$ & $33.582,2$ \\
\hline $\begin{array}{l}\text { Tabela IV Energia elétrica incorporada na produção e exportação de alguns } \\
\text { produtos primários no Brasil (2008) em Giga Watt-hora (GWh). Fonte: BERMANN, }\end{array}$ & \\
2012. Nota: GWh: milhão de quilowatt-hora (kWh). &
\end{tabular}

Estas previsões de expansão da capacidade instalada de setores industriais alimentam planos governamentais de expansão da oferta de eletricidade para criar as condições de atendimento deste insumo imprescindível e insubstituível, considerando a escala e ritmos evidenciados pelas tabelas anteriores: a eletricidade. 
Revista Tecnologia e Sociedade, Curitiba, v. 11, n. 22, 2015

Edição Especial XII Encontro Nacional de Engenharia e Desenvolvimento Social

ISSN (versão online): 1984-3526

ISSN (versão impressa): 1809-0044

O escoamento de outro recurso natural é absolutamente notável em termos de números absolutos de produção e de duração temporal. Tomemos o caso da província mineral de Carajás e a extração do minério de ferro. O Projeto Grande Carajás (PA) já vem sendo acompanhado há décadas por estudiosos como o geógrafo Ariovaldo Umbelino de Oliveira (OLIVEIRA, 1993) e pelo sociólogo e jornalista Lucio Flavio Pinto (PINTO, 1983). Estes grandes projetos, como o citado, são entendidos como intervenções extrativistas, conflitivas, com alto custo ambiental, sem trazer contrapartidas efetivas ao desenvolvimento econômico local de suas populações e regiões, que no final das contas oferecem o substrato material e social para a atividade exploratória econômica. Em atualização recente, PINTO (2014) menciona que a antiga Companhia Vale do Rio Doce, estatal privatizada em 1997, hoje Vale, sistematicamente é premiada pela presença média de alto teor $(64 \%)$ de hematita $\left(\mathrm{Fe}_{2} \mathrm{O}_{3}\right)$ contida no minério que comercializa, com ganhos médios de 3,50 dólares por tonelada (US\$1,75 por cada acréscimo de $1 \%$ no teor encontrado de hematita). Esse índice de qualidade presente no produto mineral da empresa é garantido no longo prazo pelas reservas existentes na província mineral de Carajás (PA), cuja lavra teve seu início de operação em 1985, época em que as projeções iniciais indicavam reservas calculadas em 18 bilhões de toneladas, a maior concentração de minério de ferro de alto teor (67\%) do planeta.

Segundo Pinto (2014), ao expandir sua produção, muito concentrada na mina situada ao norte da serra de Carajás, para o depósito existente ao sul em 2015, agregaria anualmente 90 milhões de toneladas à produção já verificada em 2014 de 130 milhões de toneladas de minério de ferro, quase integralmente destinada à exportação. Significa que a cada cinco anos, exportará um bilhão de toneladas, e deixará quase 300 milhões de toneladas de rejeito

O que aparentemente poderia ser considerado como um benefício econômico advindo da qualidade do minério obscurece outro aspecto da questão: ao insistir nesta rota tecnológica-comercial a empresa se mantém fundamentalmente afastada da produção siderúrgica do aço e se mantém como exportadora do minério de ferro especialmente para a China, que ao comprar grandes reservas, acumula minério do extraído do Pará, economizando energia elétrica produzida em seu território, cujo custo ambiental fica concentrado na região de origem. Resta evidente outro tipo de transposição transoceânica: de matéria e energia e com distribuição desigual da 
Revista Tecnologia e Sociedade, Curitiba, v. 11, n. 22, 2015

Edição Especial XII Encontro Nacional de Engenharia e Desenvolvimento Social

ISSN (versão online): 1984-3526

ISSN (versão impressa): 1809-0044

consequência ambiental e social da produção de grandes blocos de MWh (energia elétrica).

A sucessão de mega obras hidrelétricas previstas para serem construídas na Amazônia (onde reside o maior potencial hidrelétrico ainda a explorar nos próximos anos - ver Tabela V) é uma evidência da direção tomada pelo planejamento energético governamental para atender esta demanda. Por sua vez, tal demanda é sinalizada pelas grandes empresas exportadoras de produtos primários eletrointensivos. Trata-se de trajetória de difícil reversão a curto e médio prazo, devido à ausência de políticas industriais de longo prazo capazes de reorientar as rotas tecnológicas e a construção de cadeias produtivas, onde seja possível adicionar mais tecnologia e valor agregado e menos conteúdo de energia aos produtos exportados.

\begin{tabular}{lccc}
\hline Sub-bacia & $\begin{array}{l}\text { Potencial a } \\
\text { aproveitar (MW) }\end{array}$ & $\begin{array}{c}\text { Potencial com } \\
\text { restrições (MW) }\end{array}$ & $\begin{array}{c}\text { Potencial com } \\
\text { restrições (\%) }\end{array}$ \\
Tapajós & 24.626 & 17.841 & $72,4 \%$ \\
Xingu & 22.795 & 17.114 & $75 \%$ \\
Madeira & 14.700 & 1.556 & $10,5 \%$ \\
Tocantins & 8.202 & 7.109 & $86,6 \%$ \\
Trombetas & 6.236 & 4.745 & $76 \%$ \\
Negro & 4.184 & 4.184 & $100 \%$ \\
Araguaia & 3.095 & 3.095 & $100 \%$ \\
Jari & 1.691 & 1.373 & $81,1 \%$ \\
Branco & 1.079 & 660 & $61,1 \%$ \\
Paru & 938 & 118 & $12,5 \%$ \\
Oiapoque & 110 & 250 & $100 \%$ \\
Purus & 250 & 110 & $100 \%$ \\
Maecuru & 213 & $00 \%$ & $0 \%$ \\
Nhamundá & 161 & 161 & $100 \%$ \\
Uatumã & & 110 & \\
\hline
\end{tabular}


Revista Tecnologia e Sociedade, Curitiba, v. 11, n. 22, 2015

Edição Especial XII Encontro Nacional de Engenharia e Desenvolvimento Social

ISSN (versão online): 1984-3526

ISSN (versão impressa): 1809-0044

Total

88.355

58.529

$66,2 \%$

Tabela $\mathrm{V}$ - Restrições socioambientais ao potencial hidrelétrico por sub-bacia.

Fonte: Plano Nacional de Energia 2030. V3. Empresa de Pesquisa Energética - EPE (2007).

Com a manutenção deste perfil industrial, os danos e impactos ambientais tendem a ser crescentes, devido à necessidade de grandes projetos hidrelétricos para suprirem a demanda de energia destes setores. Do ponto de vista do esforço geral de planejamento e estabelecimento de diretrizes norteadoras de mudanças em política industrial, os planos de energia não fazem algo que seria necessário: incorporar no diagnóstico a extrema desigualdade de renda em nosso país, somos um dos piores nesse assunto.

As previsões de aumento da escala de produção da indústria intensiva no consumo de eletricidade são sinônimas de retirada crescente de recursos naturais e de energia do território nacional. Da tabela IV infere-se dado significativo: o consumo total de eletricidade nas exportações destes produtos primários de baixo beneficiamento corresponde a cerca de $8 \%$ do consumo total de eletricidade no Brasil que foi de 448073 GWh (ONS, 2015). Assim, esta parcela de energia sai do território incorporada em lingotes de alumínio, em ferro-ligas, minério de ferro papel e celulose. Trata-se de uma transposição de recursos naturais e energia com certo grau de sofisticação.

\section{COMENTÁRIOS FINAIS SOBRE SUSTENTABILIDADE AMBIENTAL DOS PROJETOS EM CONSTRUÇÃO E FUTUROS: CASOS-EVIDÊNCIA.}

Segundo recentes pesquisas e esforço de compilação desenvolvidos por Fearnside (2013), há clara concentração no programa brasileiro para expansão de usinas hidrelétricas na bacia do rio Tapajós, na qual se propõem seis barragens, no rio Tapajós e no seu afluente o Jamanxim. Estas foram incluídas no Segundo Programa de Aceleração do Crescimento, o chamado PAC-2 (2011 -2015), e juntam-se a mais cinco barragens propostas no rio Teles Pires, afluente localizado em Mato Grosso. As usinas propostas no rio Tapajós trazem junto a si a ideia da hidrovia Tapajós. Trata-se de um conjunto de barragens e eclusas que permitiriam a abertura de uma hidrovia que beneficiaria outra commodity de baixo valor agregado e de rota de exportação: a soja produzida em Mato Grosso e que se direcionaria a 
Revista Tecnologia e Sociedade, Curitiba, v. 11, n. 22, 2015

Edição Especial XII Encontro Nacional de Engenharia e Desenvolvimento Social

ISSN (versão online): 1984-3526

ISSN (versão impressa): 1809-0044

portos no rio Amazonas em Santarém. O modal prioritário no "eixo de transportes" do PAC-2 é a navegação, e uma barragem adicional seria necessária para concluir o trecho de curso de água, que não é mencionada no "eixo energia" do plano, ou seja, a barragem de Chacorão, no rio Tapajós. Apesar desta barragem não aparecer na lista de barragens planejadas para a Amazônia Legal do plano de expansão energética 2011-2020 e 2012-2021, suas eclusas são indicadas como "prioritárias" no Plano Nacional Hidroviário. A barragem de Chacorão viabilizaria a travessia de embarcações por meio da cachoeira de Sete Quedas, mas com o custo social e ambiental de inundar 18.700 ha da área indígena Munduruku, além do fato de que desmatamentos diretos ou induzidos pela consolidação da Hidrovia Tapajós não estão incluídos entre os impactos considerados no licenciamento ambiental de projetos na bacia do Tapajós, como a hidrelétrica de Teles Pires (FEARNSIDE, 2015).

De maneira geral se reconhecem os efeitos (nem sempre mencionados nos Estudos de Impacto Ambiental) de Barragens construídas em áreas com um número considerável de pessoas. $O$ resultado destes deslocamentos populacionais reforçam dinâmicas de desmatamento, de intrusão em terras indígenas, em unidades de conservação e reservas extrativistas. Outro efeito combinado ocorre pela migração espontânea de pessoas que são atraídas com a ilusão de melhores oportunidades de empregos ou de melhorias em sua condição social. A barragem de Belo Monte, hoje em construção na Volta Grande do Xingu, atraiu grande contingente populacional para a área próxima à sede urbana de Altamira (PA). Esta área tornouse um dos dois pontos de maior desmatamento em 2010 e 2011; o mesmo fenômeno ocorreu no entorno urbano próximo das barragens de Santo Antônio e Jirau, que estão em construção no rio Madeira, em Rondônia (BARRETO et al 2011; ESCADA et al, 2013; FEARNSIDE, 2013).

Existe claro avanço (real e planejado) da fronteira hidrelétrica na Amazônia, brasileira, peruana, colombiana e boliviana (FEARNSIDE, 2014), e este espaço de ampliação de projetos hidrelétricos na Amazônia diz respeito a projetos "a fio d'água", extremamente dependentes da dinâmica dos rios que assumem variações muito grandes nos valores de suas vazões quando comparamos os períodos chamado inverno e verão amazônicos. O projeto a fio d'água, em geral, tem menores áreas de reservatório, o que operacionalmente leva a uma situação de 
Revista Tecnologia e Sociedade, Curitiba, v. 11, n. 22, 2015

Edição Especial XII Encontro Nacional de Engenharia e Desenvolvimento Social

ISSN (versão online): 1984-3526

ISSN (versão impressa): 1809-0044

ineficiência intrínseca, já que a potência instalada é muito superior a potencia efetivamente desenvolvida (acionada) pelo fluxo dos rios $\left(P_{\text {máx }} \gg P_{\text {acionada }}\right)$ (HERNANDEZ, 2012).

Prevalece o Mito, construído no senso comum, da energia renovável e limpa no aproveitamento hidrelétrico: mas trata-se de conversão renovável? Temos que reconhecer que há uma confusão conceitual que envolve a renovabilidade do ciclo da água com a conversão de energia renovável. Mito este reconhecido de maneira indireta pelos resultados de análises feitas inclusive pelo setor da indústria de energia elétrica (CEBDS, 2013).

Outro aspecto diz respeito à própria vida útil de uma hidrelétrica, entendida aqui como evento técnico: hidrelétricas tem vida útil e seu descomissionamento é operação técnica recente, cujas consequências ainda são pouco conhecidas e reconhecidas, especialmente para as grandes hidrelétricas e para aquelas que seccionam rios com vazões muito grandes e que carreiam grandes volumes de sedimentos como os rios amazônicos. Este reconhecimento se dá em outros países, nos quais algumas hidrelétricas já foram descomissionadas.

Consideremos que durante sua operação, reservatórios acumulam sedimentos. As consequências ambientais desse acúmulo de material durante o descomissionamento e demolição da barragem ainda não são devidamente contabilizados. Se por um lado, a Análise do Ciclo de Vida (ACC) de Usinas Nucleares são muito conhecidas e mais discutidas, por outro, os trabalhos investigativos sobre usinas hidrelétricas se restringem a trabalhos internacionais, que algumas vezes tratam do tema associando-o aos reservatórios tropicais. Dados de estudos comparados internacionais (SLOFF, 1991; PACCA, 2003, 2007) contabilizam que para um volume de acumulação de $4900 \mathrm{~km}^{3}$ corresponderia um acúmulo de sedimentos por sua afluência no reservatório em uma taxa de $50 \mathrm{~km}^{3} /$ ano para usinas com alta capacidade instalada, o que em termos médios nos conduziriam a uma vida média de 100 anos para grandes hidrelétricas.

Esta discussão é particularmente importante no caso brasileiro, já que os planos de longo prazo como o Plano Nacional de Energia (PNE 2030) apontam a trajetória acelerada de expansão na fronteira hidrelétrica sobre a Amazônia brasileira que vem acompanhada, ao menos no âmbito discursivo, da preocupação ambiental. Um quadro de referência para identificação de problemas nos processos de 
Revista Tecnologia e Sociedade, Curitiba, v. 11, n. 22, 2015

Edição Especial XII Encontro Nacional de Engenharia e Desenvolvimento Social

ISSN (versão online): 1984-3526

ISSN (versão impressa): 1809-0044

licenciamento ambiental na chamada Amazônia hidrelétrica envolveria ao menos três conjuntos de projetos hidrelétricos brasileiros (Santo Antônio e Jirau no rio madeira, Belo Monte no rio Xingu e o chamado complexo de hidrovias e hidrelétricas no rio Tapajós e afluentes) e o acordo transfronteiriço para construção de hidrelétricas no Peru em que o Brasil se beneficiaria com $80 \%$ da energia por elas gerada em território vizinho.

\section{CASOS-EVIDÊNCIA SELECIONADOS: MADEIRA, BELO MONTE E COMPLEXO HIDRELÉTRICO DO TAPAJÓS}

Pesquisas mais recentes mostram que os procedimentos de Licenciamento Ambiental não se configuram como elementos de garantia da proteção ambiental como se poderia supor, uma vez que são instrumentos presentes dentro da Política Nacional de Meio Ambiente, em tese inserida dentro de um conjunto de práticas e tratados internacionais que envolvem a discussão pública e acesso a instrumentos de justiça nos processos de decisão que envolvam autorizações de obras com significativas consequências e riscos ambientais. Os casos mais recentes, como os da construção da Usina de Belo Monte com sua insuficiente caracterização de área diretamente afetada (MAGALHÃES \& HERNANDEZ, 2009), e Santo Antônio e Jirau no rio Madeira $(\mathrm{RO})$ com as mudanças dos contornos de unidades de conservação e Florestas Nacionais (FEARNSIDE, 2013 e 2015; HERNANDEZ, 2012) para administrativamente excluir a sobreposição de área de alagamento de usinas propostas e áreas protegidas, são reflexo de que, quando o licenciamento ambiental se torna obstáculo, aparecem decretos que suprimem medidas de proteção anteriormente aceitas. O Parque Nacional da Amazônia teve seu limite alterado pela Lei $n^{\circ} 12.678$, de 25 de junho de 2012, de modo a produzir administrativamente um resultado artificial: a ausência de superposição de áreas do parque em seus novos limites e entre as obras de engenharia e reservatório formado pela usina de São Luiz do Tapajós.

Se, pelo lado físico-ambiental, as barragens planejadas transformam a maior parte dos afluentes dos grandes rios Amazônicos e trechos deles próprios em escadas de reservatórios com compartimentação dos ecossistemas e seccionamento de fluxos migratórios de peixes e de sedimentos carreados, pelo lado 
Revista Tecnologia e Sociedade, Curitiba, v. 11, n. 22, 2015

Edição Especial XII Encontro Nacional de Engenharia e Desenvolvimento Social

ISSN (versão online): 1984-3526

ISSN (versão impressa): 1809-0044

de política ambiental os processos de licenciamento ambiental das hidrelétricas de Santo Antônio e Jirau, atualmente em fase de conclusão no rio Madeira, já criaram precedentes perigosos nesta tendência de desfiguração do licenciamento ambiental como instrumento de proteção ambiental. Os licenciamentos dos projetos no rio Madeira e no rio Xingu foram apressados, tensos e confusos, durante os quais ocorreram substituição de diretores de licenciamento ambiental e posicionamentos contrários ao licenciamento por parcela dos agentes ambientais do IBAMA envolvidos nas análises (FEARNSIDE, 2014b; HERNANDEZ \& MAGALHÃES, 2011). Substituições que ocorreram em momento em que lacunas importantes na avaliação de impactos significativos, que já haviam sido sinalizados por estudos independentes, deveriam ser esclarecidas publicamente (estudos de sedimentos, caracterização de potencial de sobrealagamento nos reservatórios de Santo Antônio e Jirau, segurança hídrica no trecho de vazão reduzida criada pela Usina de Belo Monte em trecho extenso da Volta Grande do Xingu).

De maneira mais dispersa na região, a pressão sobre áreas protegidas tem outras frentes atuantes mais antigas do que o surto hidrelétrico. Os números exibidos em tabelas anteriores mostram o avanço projetado em termos de extração de minérios. Segundo dados de 2010 (VERÍSSIMO et al, 2011), mais de 30\% das áreas protegidas da Amazônia Legal estavam sob a incidência de um total de 11.691 processos minerários e 37 solicitações de pesquisa e processos autorizados. As Unidades de Conservação estaduais de Proteção Integral são as mais afetadas, com $36 \%$ de sua área sob incidência de processos minerários. As Terras Indígenas apresentam $37 \%$ de sua extensão com incidência de processos minerários. Do total de processos incidentes, 1.338 são titulados e 10.348 são processos conhecidos como "interesses minerários", quando ainda não há autorização expedida. Sobre as Unidades de Conservação de Uso Sustentável predomina a maior quantidade de títulos incidentes e interesses minerários.

No decorrer do artigo foram explicitadas algumas tendências e expectativas de aumento da capacidade de produção de alguns setores industriais eletrointensivos. O que se imagina, em termos da teoria de planejamento, é que um conjunto de interesses e expectativas possa ser equacionado levando-se em conta uma gestão da oferta de energia, e não apenas o atendimento de uma demanda prevista isoladamente por setores de atividade econômica. Do ponto de vista das 
Revista Tecnologia e Sociedade, Curitiba, v. 11, n. 22, 2015

Edição Especial XII Encontro Nacional de Engenharia e Desenvolvimento Social

ISSN (versão online): 1984-3526

ISSN (versão impressa): 1809-0044

consequências ambientais, os modelos energéticos são moldados em função da base de recursos potencialmente a ser explorada seguindo a trajetória de ofertar a demanda prevista. Em cada etapa de operacionalização do modelo, este "se molda" em função do sistema econômico vigente, que organiza a produção criando Estruturas Sociais de Acumulação e, assim, podemos observar algumas modificações terminológicas e até mesmo conceituais: o usuário se torna consumidor; a manutenção é terceirizada (crescem acidentes fatais e interrupções no fornecimento do serviço); os órgãos licenciadores, o "ambiente" e os indígenas são encarados como problemas/entraves; e as instituições e códigos se tornam problemáticos e refletem insegurança de outra natureza: energética e ao desenvolvimento.

As expectativas de expansão da oferta de eletricidade são fundamentalmente associadas à satisfação de uma garantia de suprimento de energia. $O$ debate sobre planejamento dessa oferta é formulado a partir desse atendimento e desdobra-se, nos processos de licenciamento ambiental, em caracterizações insuficientes de consequências ambientais, sociais e técnicas do ponto de vista de um aproveitamento e uso multipolo das águas. O debate também sofre influência da pressão política. Se estivermos interessados na discussão da sustentabilidade ambiental e técnica de novos projetos, a discussão pública deve refletir a necessidade real por energia, caracterizando como ela se insere em termos de uma politica industrial que não seja predatória dos recursos naturais e que a distribuição dos benefícios seja equilibrada.

Quanto aos procedimentos de licenciamento ambiental de mega projetos, que estes tenham velocidade condizente com a qualidade requerida para uma análise diagnóstica ambiental substantiva. As condições para um planejamento mais amplo e público não se materializam dada a ramificação dos interesses econômicos associados e à concepção de que o Licenciamento Ambiental é procedimento meramente formal e obstáculo ao desenvolvimento econômico.

\section{AGRADECIMENTOS}

Este artigo rende homenagem ao intelectual, engenheiro, geógrafo, assessor de movimentos ambientalistas, de atingidos por barragens e de populações 
ameaçadas e atingidas por grandes obras de infraestrutura no Brasil. Estamos falando do Prof. Oswaldo Sevá Filho, livre docente pela Unicamp, professor das áreas de pós-graduação em energia e ciências sociais daquela universidade, engenheiro humanista, com vasta obra de pesquisa sobre os temas a que se dedicou, quais sejam, os aspectos técnicos, políticos, sociais, geográficos, ambientais dos investimentos nacionais e internacionais em obras de infraestrutura de eletricidade, mineração e metalurgia e falecido a 28 de fevereiro de 2015. A produção deste artigo teve completa influência do diálogo intelectual deste autor com o Prof. Sevá ao longo dos últimos 13 anos e foi motivado pelas discussões realizadas na conferência de abertura do XI ENEDS - Encontro Nacional de Engenharia e Desenvolvimento Social, realizado em Castanhal, PA em 24/09/2014, Encontro de Engenharia que tem como embaixador, desde 2012, o mesmo Oswaldo Sevá.

\section{REFERÊNCIAS}

Barreto, P., A. Brandão Jr., H. Martins, D. Silva, C. Souza Jr., M. Sales \& T. Feitosa. 2011. Risco de Desmatamento Associado à Hidrelétrica de Belo Monte. Instituto do Homem e Meio Ambiente da Amazônia (IMAZON), Belém, PA. 98 p. Disponível em: $<$ http://www.imazon.org.br/publicacoes/livros/risco-de-desmatamento-associado-ahidreletrica-de-belomonte/at_download/file>

BERMANN, Célio. Energia no Brasil, Para que? Para quem? São Paulo; Livraria da Física; FASE 2001.

BERMANN, Célio. O Setor de Eletro-intensivos In MOREIRA. P.F (Ed.). O Setor elétrico Brasileiro e a Sustentabilidade no Século 21: Oportunidades e desafios. - Brasília: rios internacionais - Brasil, 2012. pp 29-34.

Brasil, PR (Presidência da República). PAC-2 Relatórios. PR, Brasília, DF. 2011. Disponível em: http://www.brasil.gov.br

CEBDS - Conselho Empresarial Brasileiro para o Desenvolvimento Sustentável. Estudo sobre Adaptação e Vulnerabilidade à Mudança do Clima: o caso do setor elétrico brasileiro. 2013

EC, EUROPEAN COMMISSION, 1999. Guidelines for the Assessment of Indirect and Cumulative Impacts as well as Impact Interactions. European Commission, Luxembourg. Disponível em :<http://europa.eu.int/comm/environment/pubs/home.htm>

EPE, Empresa de Pesquisa Energética (Brasil).Plano Nacional de Energia 2030 / Ministério de Minas e Energia; colaboração Empresa de Pesquisa Energética . Brasília: MME, 2007 
Revista Tecnologia e Sociedade, Curitiba, v. 11, n. 22, 2015

Edição Especial XII Encontro Nacional de Engenharia e Desenvolvimento Social

ISSN (versão online): 1984-3526

ISSN (versão impressa): 1809-0044

EPE, Empresa de Pesquisa Energética (Brasil). Nota Técnica DEA 22/12 - Projeção da

Demanda de Energia Elétrica para os próximos 10 anos (2013-2022) (2012)

EPE, Empresa de Pesquisa Energética (Brasil). Nota Técnica DEA 28/13 - Projeção da

Demanda de Energia Elétrica para os próximos 10 anos (2014-2023) (2013)

EPA, ENVIRONMENTAL PROTECTION AGENCY (US). Consideration of Cumulative Impacts in EPA 1999. Disponível em: <www.epa.gov/compliance/resources/policies/nepa/cumulative.pdf>

FIRJAN, Federação das Industrias do Estado do Rio de Janeiro. QUANTO CUSTA A ENERGIA ELÉTRICA PARA A INDÚSTRIA NO BRASIL? Rio de Janeiro, RJ. Estudos. № 8, 2011.

FEARNSIDE, P.M. Barragens na Amazônia 7: Desmatamento no Tapajós. Amazônia Real. Dezembro de 2013. Disponível em: $<$ http://amazoniareal.com.br/barragens-na-amazonia-7-desmatamento-no-tapajos/>

FEARNSIDE, P.M. Análisis de los principales proyectos hidro-energéticos en la región amazónica. Lima: DAR, CLAES, Panel Internacional de Ambiente y Energía en la Amazonía, 2014.

FEARNSIDE, P.M. 2014b. Brazil's Madeira River dams: A setback for environmental policy in Amazonian development. Water Alternatives 7: 156-169.

FEARNSIDE, P. Amazon dams and waterways: Brazil's Tapajos Basin plans. AMBIO. 2015. DOI Disponível em: <http://dx.doi.org/10.1007/s13280-015-0642-z>

HERNANDEZ, F.D.M.; MAGALHÃES, S.M.B. Ciência, cientistas e democracia desfigurada: o caso Belo Monte. Novos Cadernos NAEA. v. 14, n. 1, p. 79-96, jun. 2011. Disponível em: <http://dx.doi.org/10.5801/ncn.v14i1.599>

HERNANDEZ, Francisco Del Moral. Hidrelétricas na Amazônia: renovabilidade e não renovabilidade da política energética. Se é desejável a renovabilidade das formas de conversão de energia, por que não é desejável renovar a política energética? Boletim do Museu Paraense

Emílio Goeldi. Ciências Humanas, v. 7, n. 3, p. 791-811, set.-dez. 2012. Disponível em: <http://dx.doi.org/10.1590/S1981-81222012000300012>

ISA, Instituto Sócio Ambiental. Análise do licenciamento ambiental do Projeto Volta Grande - Belo Sun Mineração. Manifestação em decorrência da Audiência Pública de 10/01/2013, Vila da Ressaca, Sen. José Porfírio/PA. 2013

MAB, Movimento dos Atingidos por Barragens. Curso de Formação : A Organização do Movimento dos Atingidos por Barragens - MAB. Cadernos de Formação no 5 e MAB: Uma História de Lutas. Desafios e Conquistas. Caderno 꾸 7. 2009

MAGALHÃES, S. B. Campesinato e Hidrelétricas: Uma Visão Sobre o 10 Encontro Nacional de Trabalhadores Atingidos por Barragens. IN: Hidrelétricas, ecologia e progresso: contribuições para um debate. Rio de Janeiro: CEDI, 1990.

MAGALHÃES, Sônia Barbosa. Lamento e Dor. Uma análise sócio-antropológica do deslocamento compulsório provocado pela construção de barragens. Belém, 2007. Tese (Doutorado), Ciências Sociais, Universidade Federal do Pará, Brasil; Universidade Paris 13, França, 2007. 
Revista Tecnologia e Sociedade, Curitiba, v. 11, n. 22, 2015

Edição Especial XII Encontro Nacional de Engenharia e Desenvolvimento Social

ISSN (versão online): 1984-3526

ISSN (versão impressa): 1809-0044

MAGALHÃES, S.B. e HERNANDEZ F.M. (ed.). Painel de Especialistas: Análise Crítica do Estudo de Impacto Ambiental do Aproveitamento Hidrelétrico de Belo Monte, 230 pp. Belém, PA: Painel de Especialistas sobre a Hidrelétrica de Belo Monte. 2009. Disponível em: <http://www.xinguvivo.org.br/wp-content/uploads/ 2010/10/Belo_Monte_Painel_especialistas_EIA.pdf.>

McCold, L.N. and J.W. Saulsbury. 1996. Including Past and Present Impacts in Cumulative Impact Assessments. Environmental Management. Vol. 20 no.5 pp. 767-776.

OLIVEIRA, A.U. Amazônia: monopólio, expropriação e conflitos. (4 Ed). Campinas, SP: Papirus, 1993.

ONS, Operador Nacional do Setor Elétrico. Evaporações líquidas nas usinas hidrelétricas. Relatório 3/214/2004.

ONS, Operador Nacional do Setor Elétrico. Histórico de Operação. Carga de Energia em 2008. Disponível em: < http://www.ons.org.br/historico/carga_propria_de_energia_out.aspx> Acesso em: 02/06/2015.

PACCA, Sergio. Impacts from decommissioning of hydroelectric dams: a life cycle perspective. Climatic Change 84:281-294, 2007.

PACCA, S. Global warming effect applied to electricity generation technologies. $\mathrm{PhD}$ Dissertation, University of California, Berkeley, CA, 2003.

PDE, Plano Decenal de Expansão de Energia 2020. Brasil, MME (Ministério de Minas e Energia). MME, Empresa de Pesquisa Energética (EPE). Brasília, DF. 2 vols, 2011. Disponível em: <http://www.epe.gov.br/PDEE/20111229_1.pdf>

PNE, Plano Nacional de Energia 2030. Brasil, MME (Ministério de Minas e Energia). MME, Empresa de Pesquisa Energética (EPE). Rio de Janeiro, 2007. Disponível em: <http://www.epe.gov.br/PNE/20080111_1.pdf>

PEREIRA et al. Evaporação líquida no lago de Sobradinho e impactos no escoamento devido à construção do reservatório. Revista Brasileira de Engenharia Agrícola e Ambiental v.13, n.3, p.346-352, 2009

PEREIRA, S.B. Evaporação no lago de Sobradinho e disponibilidade hídrica no rio São Francisco. Tese de Doutorado, Programa de Pós-Graduação em Engenharia Agrícola, Universidade Federal de Viçosa, Viçosa, 2004.

PINTO, L.F. Carajás: 0 ataque ao Coração da Amazônia. Marco Zero. Rio de Janeiro, 1986)

PINTO, L.F. Amazônia Real 28/08/2014

RIBEIRO, A.N.; MONTENEGRO, S.M.G.L.; Moura, A.R.C.; CIRILO, J.A. Estimativa da evaporação no lago de Sobradinho com o método do balanço de energia. XVII Simpósio Brasileiro de Recursos Hídricos, 2007.

SANCHEZ, L.E. Avaliação de impacto Ambiental: conceitos e métodos. São Paulo: Oficina de Textos , 2008. PP. 191-200. 
Revista Tecnologia e Sociedade, Curitiba, v. 11, n. 22, 2015

Edição Especial XII Encontro Nacional de Engenharia e Desenvolvimento Social

ISSN (versão online): 1984-3526

ISSN (versão impressa): 1809-0044

SANTOS,L.A.O., e ANDRADE, L.M.M. As hidrelétricas do Xingu e os povos indígenas. Comissão pró Índio de São Paulo 1988; edição em língua inglesa , Culture Survival, Boston, 1990

SEVA Fo, A.O. Nos Limites dos Riscos e da Dominação - A Politização dos Investimentos Industriais de Grande Porte. Tese de Livre Docência. DPCT/UNICAMP, Campinas,SP, 1988.

SEVA $\mathrm{F}^{\circ}, \mathrm{A} . \mathrm{O}$. Desfiguração do licenciamento ambiental de grandes investimentos (com comentário sobre as hidrelétricas projetadas no rio Xingu). Comunicação apresentada ao GT História, Sociedade e Meio Ambiente no Brasil, do $2^{\mathrm{O}}$ Encontro nacional da ANPPAS - Associação Nacional de Pós graduação e Pesquisa em Ambiente e Sociedade, Indaiatuba, SP, maio de 2004.

SEVA Fo,$A$. O (Organizador). Tenotã Mõ Alertas sobre as conseqüências dos projetos hidrelétricos no rio Xingu, Pará Brasil .Glenn SWITKES, editor, São Paulo: International Rivers Network, 2005. Disponível em: <http://www.irn.org/programs/xingu/>

SEVA $F^{\circ}, A$. Oswaldo. A era final das grandes represas e transposições entre bacias fluviais: assumir e aliviar os passivos existentes, restringir e cancelar projetos. Texto da Conferência apresentada na sessão Alternativas a las Estrategias de Grandes Obras Hidráulicas do Encuentro por una Nueva Cultura del Agua en América Latina. Fortaleza (CE), 07 dezembro de 2005.

SEVA $\mathrm{F}^{\circ}, \mathrm{A}$. Oswaldo. Tentativas hidrelétricas nos rios Xingu paraense e Madeira Mamoré internacional. Anais do II Encontro Ciências Sociais e Barragens, Sessão Temática 10 - Povos e comunidades tradicionais da Amazônia atingidas e ameaçadas por barragens. 2007

SEVA Fo ${ }^{\circ}$ A. Oswaldo. Estranhas catedrais - Notas sobre o capital hidrelétrico, a natureza e a sociedade. In: Revista Ciência e Cultura, V.60, N. 3. Saõ Paulo: SBPC, 2008, PP. 44-50.

SEVÁ $\mathrm{F}^{\circ}, \mathrm{A}$. O. Problemas intrínsecos e graves da expansão mineral, metalúrgica e hidrelétrica nas Amazônias. In: ZHOURI,A.; LASCHEFSKI,K.. (Org.). Desenvolvimento e Conflitos Ambientais. 1.ed.Belo Horizonte: Editora UFMG, 2010, v. , p. 114-147.

SLOFF, C.J. Reservoir sedimentation: a literature review, communications on hydraulic and geotechnical engineering. Report no. 91-2, Delft University of Technology, 1991.

Veríssimo, A.; ROLLA, A.; VEDOVETO, M.; FUTADA, S.M (Orgs.). Áreas Protegidas na Amazônia brasileira: avanços e desafios / Belém: Imazon; São Paulo: Instituto Socioambiental, 2011.

WATHERN, P. Environmental Impact Assesment: theory and Practice. London: Unwin Hyman, 1988.Pp 3-30.

WCD, WORLD COMMISSIONON DAMS. Dams and development: a new framework for decision making. The report of the World Comission on Dams. London, Earthscan, 2000. 